\title{
Proposal for a novel learner centered tutorial programme in biochemistry
}

\author{
Manjunath S Somannavar, Shivprasad S and Chetana K \\ Department of Biochemistry, KLE University J N Medical College, Belgaum, Karnataka, India.
}

\begin{abstract}
The aim of this paper is to suggest a novel teaching learning method in biochemistry by way of a redesigned tutorial for first year medical students. Our approach will be to incorporate the following characteristics into tutorial instructional design: allowing enough time for discussion, shifting instructor's role to facilitator, changing the role of students as learning partners, including demonstrations and practice sessions and facilitating self directed learning. The students will be divided into five groups and they will be asked to prepare for tutorials as follows; One group will present short lectures, the second group will involve itself in Multiple Choice Question setting, the third group will engage in clinical case development, the fourth group will lead the discussion through brainstorming and the fifth group will summarize the session. One person from each group will act as a presenter for one time, so that all students will get a chance subsequently. The tutor's role will be to facilitate the session. In this paper we have suggested a new design of tutorial which is learner centered as compared to the traditional type, which incorporates Gagne's conditions of learning, Merrill's principles of Instruction and Kolb's experiential learning theory.
\end{abstract}

Keywords: tutorial, biochemistry teaching, learner centered. 


\section{Introduction}

Tutorial is an important teaching-learning tool. It helps learners to enhance their intellectual, communication and social skills. In undergraduate medical education, the Medical Council of India has emphasized the need to increase small group teaching sessions [1]. Tutorial literally means a class conducted by a tutor for one student or a small number of students [2].

Tutorial classes for medical students may be conducted to develop and test their ideas, to test their understanding of subjects taught in lectures, application of new knowledge to specific problems, developing problem solving skills and encouraging students for self directed learning. Tutorials offer possibilities for discussion and interaction between students and teachers. The major advantage of tutorial oriented teaching is that all students can have the opportunity to participate and contribute, their concerns and uncertainties can be freely raised and individuals can receive rapid feedback on their ideas. The tutor's responsibility is to create an environment which encourages participation of all members of the group. [3]

In Indian medical colleges, undergraduate medical students are taught by teacher centered tutorials by near peer tutors (residents or postgraduate students) of the respective departments. These tutorial sessions are conducted for 50-75 students lasting for $30 \mathrm{~min}$ to 1 hour and it comprises of only question and answer sessions. Students are instructed to read a particular topic (displayed on notice board) for the tutorial class and they are asked questions orally for which they have to answer by recall.

There are many drawbacks of this set up. For example, no time is allotted for discussion, demonstrations are not incorporated and the students' knowledge is assessed by recall, the lowest level of cognitive thinking according to Bloom's taxonomy [4]. The tutorial program as described does not appear to develop higher order thinking skills, such as analyzing, synthesis or evaluation, decision-making and problemsolving [4]. This method also involves an instructional problem as students are not engaged in solving real world problems or applying new knowledge [5]. It also appears to hamper learning as the educational environment is not learner centered and there are no formative assessments [6].

This paper will focus on the redesign of tutorials. The authors will try to incorporate the following novel characteristics into the tutorial instructional design: Allowing enough time for discussion, supporting students as learning partners, shifting instructor's role to facilitator, including demonstrations and practice sessions, facilitating self directed learning.

\section{Method}

In this approach the students will be divided into five small groups. One person from each group will act as a presenter for one time, so that all students will eventually get a chance to participate. Students will be given one week advance intimation about the topic and they will be instructed to come prepared for their group tasks as outlined in the flowchart. The students will be instructed to approach the tutor for any clarification in preparing multiple choice questions and developing the relevant clinical case. On the day of tutorial all the students will be assembled in the tutorial hall which will be equipped with computer and projector. The tutor will welcome all the students. The presenter of the first group will deliver a short lecture on the scheduled topic for about ten minutes. The presenter of the second group will display five Multiple Choice Questions (MCQs) to the class and each group will be asked to identify the correct answer. In the next slides presenter will point out the objective in setting each of the MCQs. Group three presenters will discuss a case pertinent to the topic identified or developed by his group. Students will be encouraged to use pictures and videos in presenting their case. Group 4 presenter will discuss the answer for long essay question they have chosen. Group 
5 presenter will summarize the session. During the initial few sessions, the students will be trained for summarizing. The Tutor will facilitate the session and also give feedback to students. The Tutor will end the session after giving assignments for the group task. A model of group tasks is presented in the appendix.

\section{Discussion}

Gagne has identified nine phases of learning and has applied cognitive processes concepts to the analysis of learning [7].This tutorial redesign encompasses Gagne's nine phases of learning as described below. Group task and short lecture at the beginning alert the learner to the stimulus (Attending), orient the students to the learning goal (Expectancy) and provide relevant information (Retrieval). MCQs enhance Selective perception of stimulus features. Identifying or developing a case related to the topic transfers stimulus features and related information to long term memory. Discussion activates response (retrieval and responding). Summarizing confirms student's expectancy about learning goal. Feedback and assignments provide additional cues for later recall of the capability (Cueing retrieval) and enhance transfer of learning (Generalisability). According to Merrill learning is promoted when new knowledge is applied by students in solving real world problems [5].

The proposed design promotes learning as students will be developing or identifying cases and solving MCQs. Merrill stresses the importance of demonstrating information via specific cases or situations [5]. The proposed design helps in developing higher order thinking skills of Bloom's taxonomy. For example solving MCQs (Application, Internalize), developing a case (Synthesis, Organize, Articulation).

In Experiential Learning model Kolb postulated that learning occurs through cycle of four processes [8]. Reading assignments and group tasks help to attain concrete experience. Discussion and Brainstorming through questions can help students recognize their observations(Reflective Observation).Lecture ,summarizing and discussing objectivity of setting MCQs help students to conceptualize their ideas(Abstract conceptualization). Case study discussion and solving MCQs lead to experimentation (Active Experimentation). Assignments given as home work enables students to have more concrete experience.

Researchers feel that students should develop the ability to teach themselves [6]. This proposal can help students in metacognition as it involves active participation in preparation of pedagogical content knowledge.

In one of the studies on students led objective tutorial authors have found that incorporating objective MCQs promotes active learning and self directed learning in small groups. They have also reported that students appreciated the full participation in preparation, led to learning and also content reached uniformly to all students. Major disadvantage in their study was time consuming aspect of tutorial preparation [9].

\section{Conclusion}

Medical education in India is at a crucial stage of waiting to change. In this paper we have proposed a new style of tutorial which is learner centered compared to traditional type. We believe this work works and will be accepted by students and teaching faculty. Challenges will be motivating students and tutors to spare time for preparation for tutorial sessions.

\section{Reference}

1. Medical Council of India. Undergraduate Medical Education Regulation. Gazette of India: Part III, section 4; 1997. 
2. Merriam-Webster Online Dictionary. [Monograph on the Internet]. Springfield (MA): Merriam Webster; 2006. [Accessed May 2010]. Available from: http://www.merriamwebster.com

3. James R. and Baldwin G. Tutoring and demonstrating: a guide for the University of Melbourne. Available from: http:///www.cshe.unimelb.edu.au/bookpage s/chap 1.html.[Accessed May 2010]

4. Chapman A. Explanation of Bloom's Taxonomy of Learning Domains, December 2006, Accessed May 26th 2010, available from:

http://www.businessballs.com/bloomstaxono myoflearningdomains.htm

5. Merrill $D$ M. First Principles of Instruction.ETR\&D, Vol 50, No.3, 2002, pp 4359

6. Bransford, John D, Ann L Brown and Rodney R. Cocking (Eds.) How People Learn: brain, mind, experience and school. Washington, DC: National Academy Press

7. Gagne, R. (1985). The Conditions of Learning (4th ed.). New York: Holt, Rinehart \& Winston

8. Kolb D. (1984). Experiential learning: Experience as the source of learning and development. Englewood Cliffs, NJ: Prentice Hall

9. Sivagnanam G, Sarawathi S, Rajasekaran A. Student-led objective tutorial (SLOT) in medical education. Med Educ Online [serial online] 2006; 11:7 Available from http://www.med-ed-online.org 


\section{Appendix}

Group-1

\section{Minilecture}

Functions of liver

Liver Function Tests

Tests based on excretory function-Seum Bilirubin

Urinary Bilirubin,

Bile salts and urobilinogen

Tests based on Synthetic function of liver- Serum total protein, Albumin and AG ration

Prothrombin time

Tests based on serum enzymes- enzymes indicating hepatocellular damage

Marker enzymes of obstructive liver disease

\section{Group-2}

\section{Relevant Clinical Case presentation}

A 40-year old businessman attended the outpatient clinic with complaints of fever, loss of appetite, yellow discoloration of the eyes, passing of dark colored urine and itching of the whole body for the past 1 week. He denied history of similar attacks in the past. He did not consume alcohol regularly. The following are the biochemical investigations done:

$\begin{array}{llll}\text { Alanine aminotransferase (ALT) } & - & 320 \mathrm{IU} / \mathrm{L} & (13-40 \mathrm{IU} / \mathrm{L}) \\ \text { Aspartate aminotransferase (AST) } & - & 220 \mathrm{IU} / \mathrm{L} & (8-20 \mathrm{IU} / \mathrm{L}) \\ \text { Alkaline phosphatase (ALP) } & - & 40 \mathrm{IU} / \mathrm{L} & (40-125 \mathrm{IU} / \mathrm{L}) \\ \text { Total serum protein } & - & 7.5 \mathrm{~g} / \mathrm{dl} & (6-8 \mathrm{~g} / \mathrm{dl}) \\ \text { Albumin } & - & 4.2 \mathrm{~g} / \mathrm{dl} & (3.5-5.0 \mathrm{~g} / \mathrm{dl}) \\ \text { Globulin } & - & 3.3 \mathrm{~g} / \mathrm{dl} & (2.5-3.5 \mathrm{~g} / \mathrm{dl}) \\ \text { Serum total bilirubin } & - & 6 \mathrm{mg} / \mathrm{dl} & (0.2-1 \mathrm{mg} / \mathrm{dl}) \\ \text { Direct bilirubin } & - & 4.2 \mathrm{mg} / \mathrm{dl} & (0-0.2 \mathrm{mg} / \mathrm{dl}) \\ \text { Indirect bilirubin } & - & 1.8 \mathrm{mg} / \mathrm{dl} & (0.2-0.8 \mathrm{mg} / \mathrm{dl})\end{array}$

Urinary findings

bile salts +

bile pigments ++

urobilinogen -+

1. What type of jaundice does this patient likely to have? Give reasons for your answer by interpreting the laboratory results. 
Group-3

\section{Multiple Choice Questions}

1. Which of the following condition is associated with Conjugated hyperbilirubinemia and raised alkaline phosphatase levels?

a. Hepatocellular jaundice

b. Obstructive jaundice

c. Haemolytic jaundice

d. Neonatal physiological jaundice

Objective for setting the MCQ

Alkaline Phosphatase is the marker enzyme for obstructive liver disease

Group-4

Writing answer for long essay question.

a. Discuss the formation and excretion of bilirubin by liver.

Corresponding Author: Dr Manjunath S Somannavar, Department of Biochemistry, KLE University J N Medical College, Belgaum, Karnataka, India.. Email: manjunathsomannavar@gmail.com 